\title{
IIIness representation, beliefs about medicines and knowledge of disease risk factors in cardiac patients
}

\author{
Marina Njegovan ${ }^{1 *}$, Viktor Peršić1 ${ }^{1}$ Eris Materljan² \\ ${ }^{1}$ Thalassotherapia Opatija - Clinic for treatment, rehabilitation and prevention of cardiovascular \\ disease, Opatija, Croatia \\ ${ }^{2}$ University of Rijeka School of Medicine, Rijeka, Croatia
}

\begin{abstract}
Objective: Illness perception is an important determinant of psychological well-being and functional outcomes in patients with chronic diseases. When patients face the disease, they actively create an organized pattern of beliefs about their condition in order to give the meaning to the experience of illness. Individual model of illness is not always medically accurate, but it is logical and rational from patient's personal point of view. It affects the emotional response to the disease as well as behaviors associated with disease. According to Leventhal's theory of self-regulation, adherence to medical recommendations necessary for adequate (secondary) disease prevention, is determined by an individual model of the disease. A number of studies has showed the correlation between generally negative illness perception and increased future disability as well as slower functional recovery, regardless of the initial medical severity of the condition. This study sought to examine illness representations in cardiac patients, as well as their attitudes about the prescribed medicines and knowledge of disease risk factors.
\end{abstract}



Method: The sample consisted of 70 cardiac patients involved in the program of cardiac rehabilitation after myocardial infarction or coronary artery bypass surgery. The brief illness perception questionnaire, Beliefs about medicines questionnaire and Cardiovascular disease risk factors knowledge level scale were administered.

Results: Most of the patients perceive their illness to be chronic but susceptible to a relatively good personal control and especially the treatment control. They don't associate many symptoms with their illness and have lower levels of concern and emotional response, as well as a good sense of comprehension of illness. Most of them also do not perceive their condition as the one with major consequences. According to patients, the most important causes of illness are stress, heritage and lifestyle. Benefits of the prescribed medicines are generally perceived to overweigh potential adverse effects, although $10 \%$ of respondents show a negative attitude toward the prescribed medicines.

Global illness perception, knowledge of the disease risk factors and diagnosis are shown to be significant predictors of attitudes toward medicines.

KEYWORDS: illness perception, beliefs about medicines, knowledge of risk factors.

CITATION: Cardiol Croat. 2014;9(5-6):252.

\section{Literature}

1. Byrne M, Walsh J, Murphy AW. Secondary prevention of coronary heart disease: patient beliefs and health-related behaviour. J Psychosom Res. 2005;58(5):403-15.

2. Petrie KJ, Weinman J. Why illness perception matter. Clin Med. 2006;6(6):536-9.

3. Mitković M, Ristić L, Žikić O, Milošević V, Grbeša G. Percepcija bolesti u hroničnoj opstruktivnoj bolesti pluća. Med Pregl. 2010;63(3-4):179-82. 